\title{
Anatomic stemless shoulder arthroplasty and related outcomes: a systematic review
}

Nael Hawi ${ }^{1,2^{*}}$, Mark Tauber ${ }^{1,3}$, Michael Joseph Messina ${ }^{1,4}$, Peter Habermeyer ${ }^{1}$ and Frank Martetschläger ${ }^{1,5}$

\begin{abstract}
Background: The latest generation of shoulder arthroplasty includes canal-sparing respectively stemless designs that have been developed to allow restoration of the glenohumeral center of rotation independently from the shaft, and to avoid stem-related complications. The stemless prosthesis design has also recently been introduced for use in reverse arthroplasty systems.

Methods: We systematically reviewed the literature for studies of currently available canal-sparing respectively stemless shoulder arthroplasty systems. From the identified series, we recorded the indications, outcome measures, and humeral-sided complications.

Results: We identified 11 studies of canal-sparing respectively stemless anatomic shoulder arthroplasty implants, published between 2010 and 2016. These studies included 929 cases, and had a mean follow-up of 26 months (range, 6 to 72 months). The rates of humeral component-related complications ranged between 0 and $7.9 \%$. The studies reported only a few isolated cases of complications of the humeral component. Some arthroplasty systems are associated with radiological changes, but without any clinical relevance.

Conclusions: All of the published studies of canal-sparing respectively stemless shoulder arthroplasty reported promising clinical and radiological outcomes in short to midterm follow-up. Long-term studies are needed to demonstrate the long-term value of these kind of implants.

Keywords: Shoulder arthroplasty, Stemless, Canal-sparing, Total shoulder arthroplasty, Shoulder arthritis, Posttraumatic shoulder arthritis

Abbreviations: $E R$, external rotation; IR, internal rotation; CTA, cuff tear arthropathy; MRCT, massive rotator cuff tear; VAS, Visual Analog Scale; SPADI Index, Shoulder Pain and Disability Index; DASH Score, Disabilities of the Arm, Shoulder and Hand Score; ASES Score, American Shoulder and Elbow Surgeons Shoulder Score; WOOS Index, Western Ontario Osteoarthritis Shoulder Index; e.g., For example; etc., Et cetera
\end{abstract}

\section{Background}

Early development of shoulder arthroplasty can be traced back to 1950s when Charles Neer, II, described the use of an implant to treat a proximal humeral fracture [1]. Eventually, the indication was widened to include osteoarthritis treatment. Since Neer's initial prosthesis, the humeral stem design has undergone several changes. Results of total shoulder arthroplasty were first presented in 1974 [2]. The following years saw the introduction of several

\footnotetext{
* Correspondence: hawi.nael@mh-hannover.de

'Department of Shoulder and Elbow Surgery, ATOS Clinic Munich,

Effnerstraße 38, 81925 München, Germany

${ }^{2}$ Trauma Department, Hannover Medical School, Carl-Neuberg-Str. 1, 30625

Hannover, Germany

Full list of author information is available at the end of the article
}

variations of stemmed humeral implants, which could be subdivided into four different generations. Stem design initially used a monoblock system, then changed to a modular system, followed by a shift to the use of shorter stems. Additionally, cemented fixation techniques have been replaced over time by a press-fit cementless system. The use of shorter implant stems and the elimination of humeral cement carry several advantages, including the preservation of humeral bone stock for potential revisions, performance of anatomic reconstruction regardless of posterior offset in anatomic arthroplasty, facilitating arthroplasty in cases of humeral deformity, prevention of malpositioning, and avoiding periprosthetic fractures [3]. 
Commonly reported stem-related complications include intraoperative humeral fracture, loosening, stress shielding, and traumatic periprosthetic fracture [4-11]. Fracture sequelae, including severe shaft-head malunion, can lead to malalignment of the shaft implantation and a failure to restore the anatomic center of rotation. In revision surgery, stem removal can present a challenge for the surgeon, potentially requiring an osteotomy or inadvertently resulting in an intraoperative fracture $[5,6,8$, 11]. Canal-sparing respectively stemless prostheses were first available in Europe in 2004. Such implants lack a conventional diaphyseal humeral stem, are based on metaphyseal fixation, and do not violate the humeral canal. In this review article, the terms "canal-sparing" respectively "stemless" refer to implant designs with metaphyseal fixation using a standard humeral neck cut, and excluding humeral head resurfacing techniques. Canalsparing respectively stemless shoulder arthroplasty must not be confused with resurfacing techniques that aim to restore joint congruency by preserving the majority of the humeral head bone stock and implantation of a metallic cap over the remaining humeral head bone stock [3, 12-18].

Here we have systematically reviewed the current literature describing canal-sparing respectively stemless prostheses in shoulder arthroplasty, particularly with regards to clinical outcomes and complications related to the humeral components.

\section{Methods}

The senior investigator (FM) and first author (NH) systematically scanned an online database system (Pubmed, Google Scholar) using the MeSH terms "stemless", "shoulder replacement", "shoulder arthroplasty", "canal-sparing", and "short stem". Then the resulting list of references was reviewed to identify potential additional studies. Inclusion criteria were clinical studies including more than five patients, using cementless and stemless humeral fixation, and presenting outcomes and complications.

Statistical analysis was ineffective due to the small number of cases, as well as the use of different follow-up protocols, study designs, and outcome measures. Therefore, we performed a descriptive review, with information presented according to the different investigated prosthetic designs. For all included series, we recorded and summarized the indications, outcome measures (clinical and radiological), and complications. The scoring systems of the different studies are presented systematically. Only complications related to the humeral component are included.

\section{Results}

Our findings are summarized in Tables 1, 2, 3, 4 and 5.

\section{Biomet Total Evolutive Shoulder System}

The first available canal-sparing respectively stemless implant was the Biomet Total Evolutive Shoulder System (TESS, Biomet, Warsaw, IN, USA), which was first used in Europe in 2004 (Fig. 1). The TESS is a three-component system, which includes an impaction-implanted 6-armed corolla that is porous to improve bone ingrowth. We identified five studies using the TESS, which were published between 2010 and 2016, and included a total of 155 patients. Follow-up times ranged from 6 to 45 months. Table 2 presents the surgical indications. All studies showed clinical improvement after arthroplasty compared to the preoperative status.

In 2010, Huguet et al. [19] first reported on 63 cases with a minimum follow-up of three years. Concerning the TESS stemless humeral implant, the authors report that in five cases the lateral cortex cracked during

Table 1 Included patients and follow-up

\begin{tabular}{|c|c|c|c|c|c|c|}
\hline & & & Implant & $\mathrm{n}=$ included stemless & Age (years, mean) & FU (months, mean) \\
\hline 2010 & Huguet et al. & JSES & TESS & 63 & 64 & 45.2 \\
\hline 2013 & Razmjou et al. & JSES & TESS & 17 & 69 & 24 \\
\hline 2013 & Berth et Pap & JOT & TESS & 41 & 67 & 30.8 \\
\hline 2015 & Maier et al. & $\mathrm{BMC}$ & TESS & 12 & 68 & 6 \\
\hline 2011 & Kadum et al. & AOTS & TESS & 22 & 71 & 14 \\
\hline \multirow[t]{2}{*}{2014} & Bell et Coghlan & Int J Shoulder Surg & Mathys Affinis & 38 & 68 & 12 \\
\hline & & & & 12 & 65 & 24 \\
\hline \multirow[t]{2}{*}{2011} & Schoch et al. & Obere Extremitaet & Arthrex Eclipse & 96 & 66 & 13.2 \\
\hline & & & & 19 & 62 & \\
\hline 2012 & Brunner et al. & Obere Extremitaet & Arthrex Eclipse & 233 & 61 & 23.2 \\
\hline 2015 & Habermeyer et al. & JSES & Arthrex Eclipse & 78 & 58 & 72 \\
\hline 2016 & Ho et al. & JSES & Simpliciti & 149 & 66 & 24 \\
\hline 2016 & Churchill et al. & JBJS & Simpliciti & 149 & 66 & 24 \\
\hline
\end{tabular}


Table 2 Indication for stemless arthroplasty treatment

\begin{tabular}{|c|c|c|c|c|c|c|c|c|c|c|c|c|c|c|}
\hline & & & Implant & $\begin{array}{l}\mathrm{N} \\
\text { (stemless) }\end{array}$ & $\begin{array}{l}\text { Primary } \\
\text { osteoarthritis }\end{array}$ & $\begin{array}{l}\text { Posttraumatic } \\
\text { osteoarthritis }\end{array}$ & $\begin{array}{l}\text { Osteo- } \\
\text { necrosis }\end{array}$ & $\begin{array}{l}\text { Rheumatoid } \\
\text { arthritis }\end{array}$ & CTA & MRCT & $\begin{array}{l}\text { Instability } \\
\text { arthritis }\end{array}$ & $\begin{array}{l}\text { Post } \\
\text { infection } \\
\text { arthtis }\end{array}$ & $\begin{array}{l}\text { Arthritis due to } \\
\text { glenoid } \\
\text { dysplasia }\end{array}$ & Revision \\
\hline 2010 & Huguet et al. & JSES & TESS & 63 & 60 & & 3 & & & & & & & \\
\hline 2013 & Razmjou et al. & JSES & TESS & 17 & 17 & & & & & & & & & \\
\hline 2013 & Berth et Pap & JOT & TESS & 41 & 41 & & & & & & & & & \\
\hline 2015 & Maier et al. & $\mathrm{BMC}$ & TESS & 12 & 12 & & & & & & & & & \\
\hline 2011 & Kadum et al. & AOTS & TESS & 22 & 19 & & & 3 & & & & & & \\
\hline 2014 & Bell et Coghlan & $\begin{array}{l}\text { Int J } \\
\text { Shoulder } \\
\text { Surg }\end{array}$ & $\begin{array}{l}\text { Mathys } \\
\text { Affinis }\end{array}$ & 50 & 50 & & & & & & & & & \\
\hline 2011 & Schoch et al. & $\begin{array}{l}\text { Obere } \\
\text { Extremitaet }\end{array}$ & $\begin{array}{l}\text { Arthrex } \\
\text { Eclipse }\end{array}$ & 115 & 96 & 19 & & & & & & & & \\
\hline 2012 & Brunner et al. & $\begin{array}{l}\text { Obere } \\
\text { Extremitaet }\end{array}$ & $\begin{array}{l}\text { Arthrex } \\
\text { Eclipse }\end{array}$ & 233 & 100 & 70 & 6 & 16 & 3 & & 29 & 4 & & $\begin{array}{l}5 \text { cases } \\
\text { couldn't } \\
\text { assigned }\end{array}$ \\
\hline 2015 & Habermeyer et al. & JSES & $\begin{array}{l}\text { Arthrex } \\
\text { Eclipse }\end{array}$ & 78 & 39 & 26 & & & 3 & & 8 & 1 & 1 & \\
\hline 2016 & Ho et al. & JSES & Simpliciti & 149 & & & & & & & & & & $\begin{array}{l}\text { Not } \\
\text { specified }\end{array}$ \\
\hline 2016 & Churchill et al. & JBJS & Simpliciti & 149 & $96 \%$ & $4 \%$ & & & & & & & & \\
\hline
\end{tabular}


Table 3 Kind of stemless arthroplasty treatment and approach

\begin{tabular}{|c|c|c|c|c|c|c|c|c|}
\hline & & & Implant & $n$ & Approach & Hemiarthroplasty & $\begin{array}{l}\text { Total shoulder } \\
\text { arthroplasty }\end{array}$ & \\
\hline 2010 & Huguet et al. & JSES & TESS & 63 & Deltopectoral & 44 & 19 & \\
\hline 2013 & Razmjou et al. & JSES & TESS & 17 & Deltopectoral & & 17 & \\
\hline 2013 & Berth et Pap & JOT & TESS & 41 & Deltopectoral & & 41 & \\
\hline 2015 & Maier et al. & BMC & TESS & 12 & Deltopectoral & & 12 & \\
\hline 2011 & Kadum et al. & AOTS & TESS & 22 & $\begin{array}{l}\text { Antero-Superior } \\
\text { (Mackenzie) }\end{array}$ & & & $\begin{array}{l}\text { Not } \\
\text { assigned }\end{array}$ \\
\hline 2014 & Bell et Coghlan & $\begin{array}{l}\text { Int J Shoulder } \\
\text { Surg }\end{array}$ & $\begin{array}{l}\text { Mathys } \\
\text { Affinis }\end{array}$ & 50 & Deltopectoral & & 50 & \\
\hline 2011 & Schoch et al. & $\begin{array}{l}\text { Obere } \\
\text { Extremitaet }\end{array}$ & $\begin{array}{l}\text { Arthrex } \\
\text { Eclipse }\end{array}$ & 115 & Deltopectoral & & 115 & \\
\hline 2012 & Brunner et al. & $\begin{array}{l}\text { Obere } \\
\text { Extremitaet }\end{array}$ & $\begin{array}{l}\text { Arthrex } \\
\text { Eclipse }\end{array}$ & 233 & Deltopectoral & 114 & 119 & \\
\hline 2015 & $\begin{array}{l}\text { Habermeyer et } \\
\text { al. }\end{array}$ & JSES & $\begin{array}{l}\text { Arthrex } \\
\text { Eclipse }\end{array}$ & 78 & Deltopectoral & 39 & 39 & \\
\hline 2016 & Ho et al. & JSES & Simpliciti & 149 & Deltopectoral & & 149 & \\
\hline 2016 & Churchill et al. & JBJS & Simpliciti & 149 & Deltopectoral & & 149 & \\
\hline
\end{tabular}

surgery without any sign of instability, and that each of these cases healed without further intervention. No other humeral implant-associated complications or problems were noted.

The remaining four identified studies reported no complications related to the TESS humeral implant. Kadum et al. [20] analyzed 56 patients, among whom 22 received an anatomic TESS prosthesis, with a mean follow-up of 14 months. Razmjou et al. [21] compared the anatomic TESS prosthesis $(n=17)$ to the Bigliani-Flatow $(n=40)$ and the Neer II prosthesis $(n=22)$, showing no significant differences in outcome between groups, with a mean follow-up of 24 months. Berth and Pap [22] compared the anatomic TESS prosthesis to the Mathys Affinis stemmed prosthesis, with 41 patients in each group and a mean follow-up of 30 months. Their results revealed no statistically significant differences in outcome. Finally, Meier et al. [23] compared the anatomic TESS prosthesis to the anatomic stemmed Aequalis Shoulder prosthesis (Tournier, Lyon, France), with 12 cases per group and a 6month follow-up. They reported comparable results for both groups based on the Constant Score.

Table 4 Humeral implant related complication

\begin{tabular}{|c|c|c|c|c|c|c|}
\hline & & & Implant & $n$ & $\begin{array}{l}\text { Percentage of } \\
\text { complication }\end{array}$ & $\begin{array}{l}\text { Kind of stemless humeral implant related complication and } \\
\text { treatment }\end{array}$ \\
\hline 2010 & Huguet et al. & JSES & TESS & 63 & $7.9 \%$ & $\begin{array}{l}\text { - Five patients with a small crack of the humeral } \\
\text { lateral cortex intraoperatively, noticed on the first } \\
\text { postoperative radiograph, further conservative treatment }\end{array}$ \\
\hline 2013 & Razmjou et al. & JSES & TESS & 17 & $0 \%$ & - \\
\hline 2013 & Berth et Pap & JOT & TESS & 41 & $0 \%$ & - \\
\hline 2015 & Maier et al. & BMC & TESS & 12 & $0 \%$ & - \\
\hline 2011 & Kadum et al. & AOTS & TESS & 22 & $0 \%$ & - \\
\hline 2014 & $\begin{array}{l}\text { Bell et } \\
\text { Coghlan }\end{array}$ & $\begin{array}{l}\text { Int J Shoulder } \\
\text { Surg }\end{array}$ & $\begin{array}{l}\text { Mathys } \\
\text { Affinis }\end{array}$ & 50 & $0 \%$ & - \\
\hline 2011 & Schoch et al. & $\begin{array}{l}\text { Obere } \\
\text { Extremitaet }\end{array}$ & $\begin{array}{l}\text { Arthrex } \\
\text { Eclipse }\end{array}$ & 115 & $0 \%$ & - \\
\hline 2012 & Brunner et al. & $\begin{array}{l}\text { Obere } \\
\text { Extremitaet }\end{array}$ & $\begin{array}{l}\text { Arthrex } \\
\text { Eclipse }\end{array}$ & 233 & $2.3 \%$ & $\begin{array}{l}\text { - One patient with radiological and asymptomatic loosening } \\
\text { after } 24 \text { months }\end{array}$ \\
\hline 2015 & $\begin{array}{l}\text { Habermeyer } \\
\text { et al. }\end{array}$ & JSES & $\begin{array}{l}\text { Arthrex } \\
\text { Eclipse }\end{array}$ & 78 & $0 \%$ & - \\
\hline 2016 & Ho et al. & JSES & Simpliciti & 149 & $0 \%$ & - \\
\hline 2016 & Churchill et al. & JBJS & Simpliciti & 149 & $0 \%$ & - \\
\hline
\end{tabular}


Table 5 Outcome parameters with radiological humeral conspicuous findings (values are given in mean if not declared different)

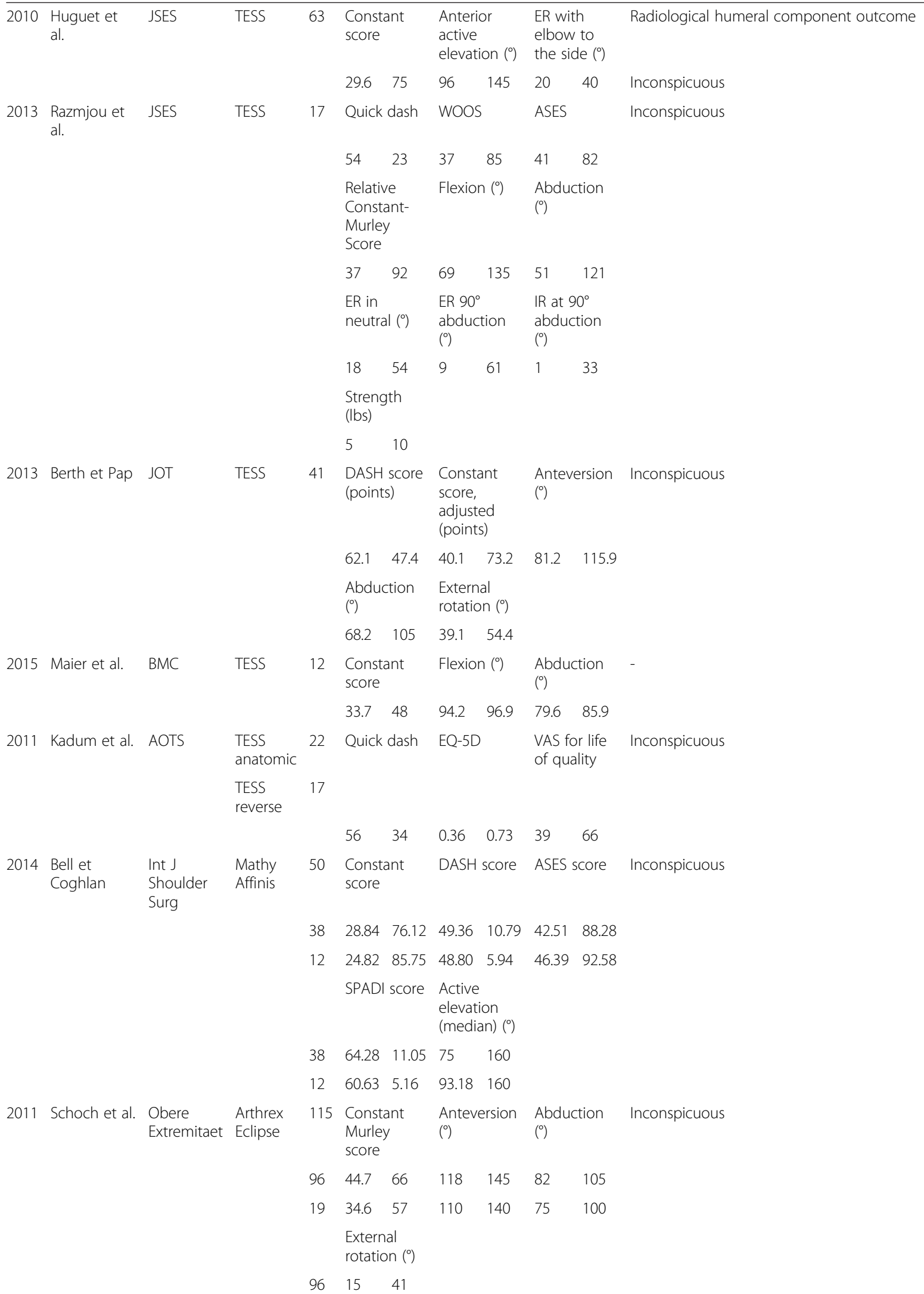


Table 5 Outcome parameters with radiological humeral conspicuous findings (values are given in mean if not declared different) (Continued)

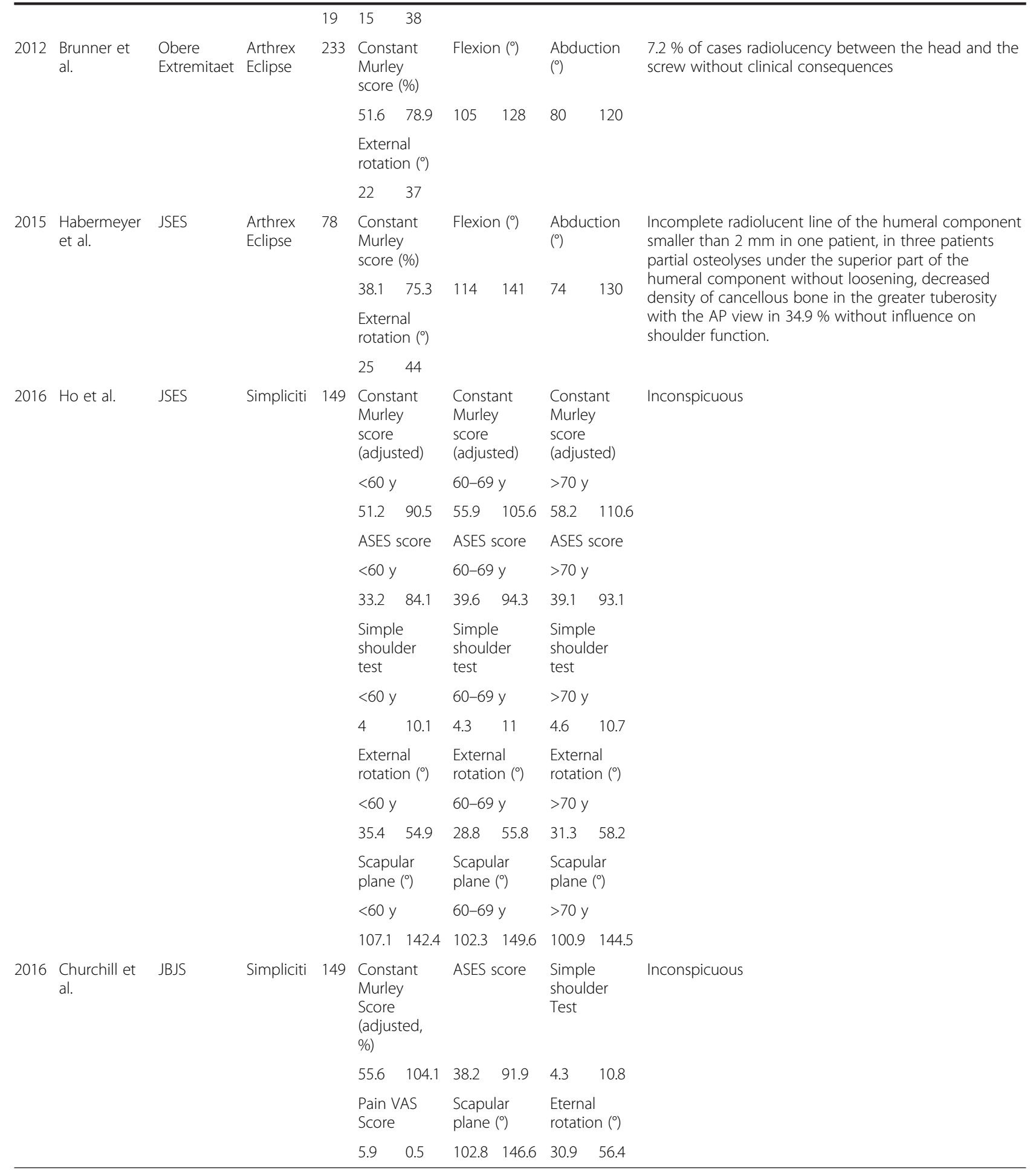

\section{Mathys Affinis Short Stemless Prosthesis}

The Mathys Affinis Short Stemless Prosthesis (Mathys, Betlach, Switzerland) was first available on the European market in 2009 (Fig. 2). This arthroplasty system has two components: a humeral metaphyseal implant and a ceramic humeral head. The metaphyseal implant comprises four 


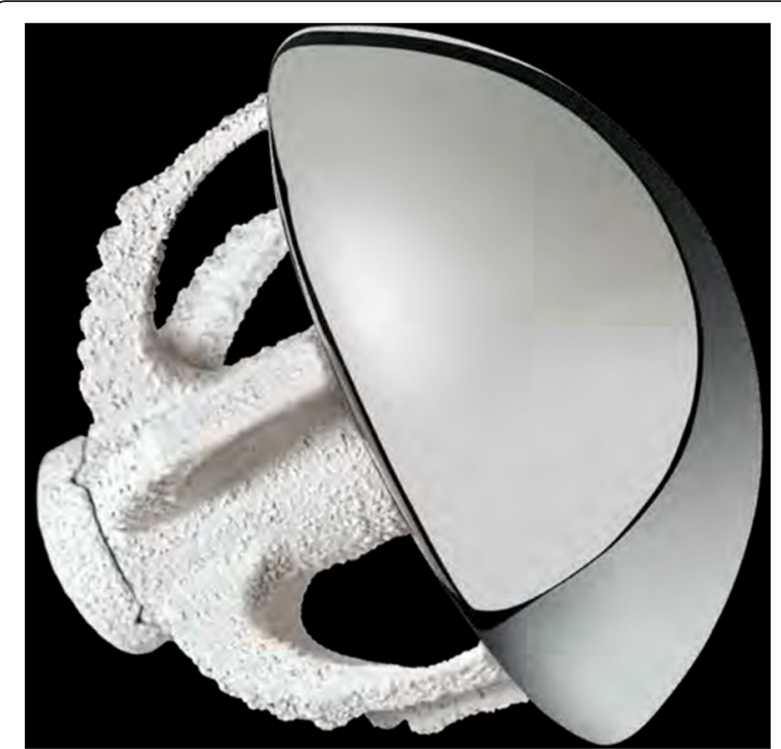

Fig. 1 The Biomet Total Evolutive Shoulder System (TESS; Biomet, Warsaw, IN, USA) (Figure provided by the manufacturer)

wings composed of a rough porous titanium structure, with an osteoconductive calcium phosphate coating to improve bone ingrowth. This part is inserted with impaction.

In the only published study using this implant, Bell and Coghlan [24] investigated 50 cases with an indication of primary osteoarthritis. They reported a 24-month followup for 12 cases, and a 12-month follow-up for 38 cases. No prosthesis-related intraoperative or postoperative complications were reported.

\section{Arthrex Eclipse Prosthesis}

The Arthrex Eclipse Prosthesis (Arthrex, Naples, USA) was introduced in 2005 (Fig. 3). This prosthesis comprises three components. A fully threaded, cylindrical

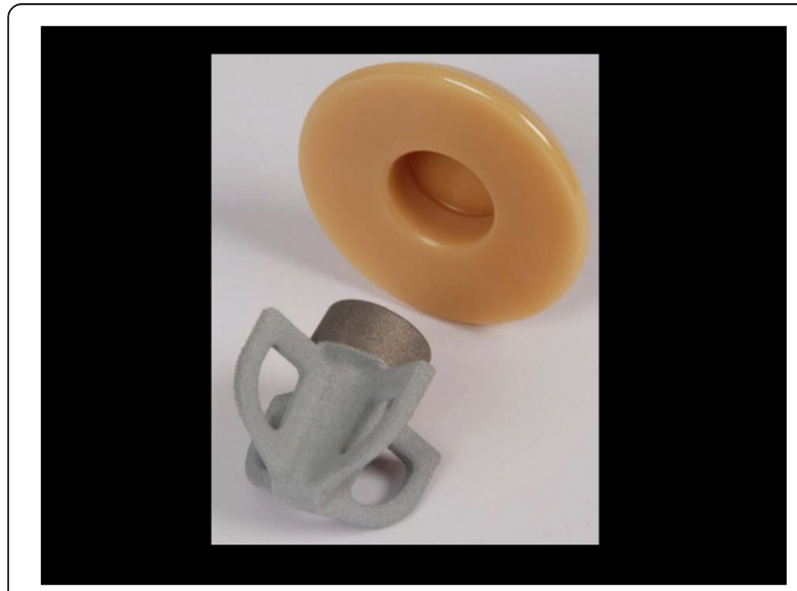

Fig. 2 The Mathys Affinis Short Stemless Prosthesis (Mathys, Betlach, Switzerland) (Figure provided by the manufacturer)

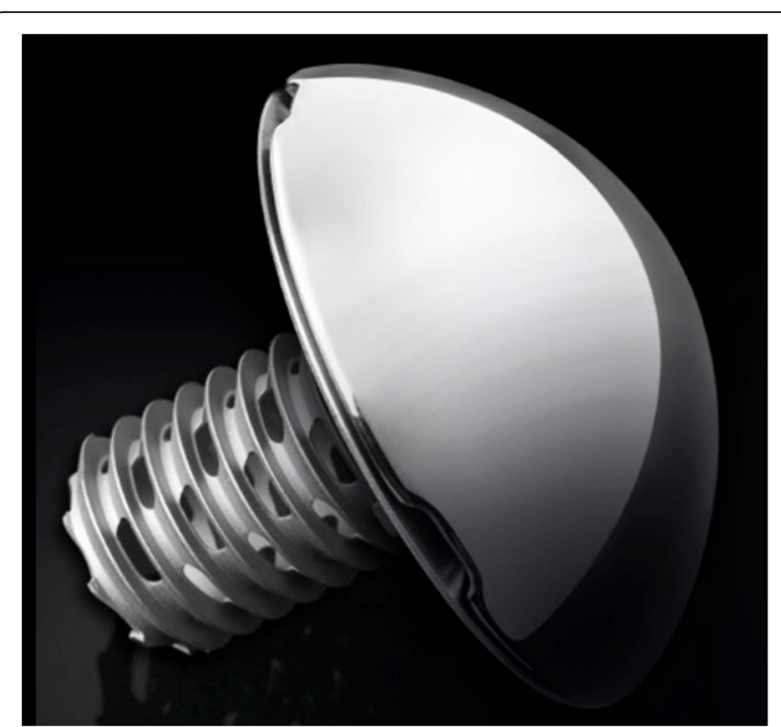

Fig. 3 The Arthrex Eclipse Prosthesis (Arthrex, Naples, USA) (Figure provided by the manufacturer)

central cage unit is inserted over a collar-bearing baseplate (trunnion) for metaphyseal fixation. The trunnion covers the resection plane at the anatomical neck, and joins cortical support. The third component is a corresponding humeral head. In contrast to the other described implants, the Arthrex Eclipse is the only available stemless system that offers screw-in insertion.

Between 2011 and 2015, three studies investigated the Eclipse prosthesis, including a total of 426 procedures with a mean follow-up ranging from 13 to 72 months. Table 2 presents the specific surgical indications. Schoch et al. [25] analyzed 115 cases, and reported that all of the radiographs evaluated at the 12-month follow-up were inconspicuous with regards to loosening or radiolucent lines. Brunner et al. [26] published their experience of using the Eclipse prosthesis in 233 patients after a mean follow-up of 23 months. They describe one case in which the implant loosened after 24 months, and they noted radiolucency between the head and the screw in $7.2 \%$ of cases. However, these radiological changes did not appear to have any clinical relevance.

In the most recent study of the Eclipse prosthesis, Habermeyer et al. [27] analyzed 78 patients with a minimum follow-up of 5 years. They reported that one patient showed an incomplete radiolucent line of the humeral component of smaller than $2 \mathrm{~mm}$. Additionally, three patients exhibited partial osteolysis under the superior part of the humeral component, without loosening of the component. Among the patients, $34.9 \%$ showed changed cancellous bone density in terms of stress shielding at the greater tuberosity on the AP view, without clinical significance. No implant-specific complications were observed related to the Eclipse prosthesis. 


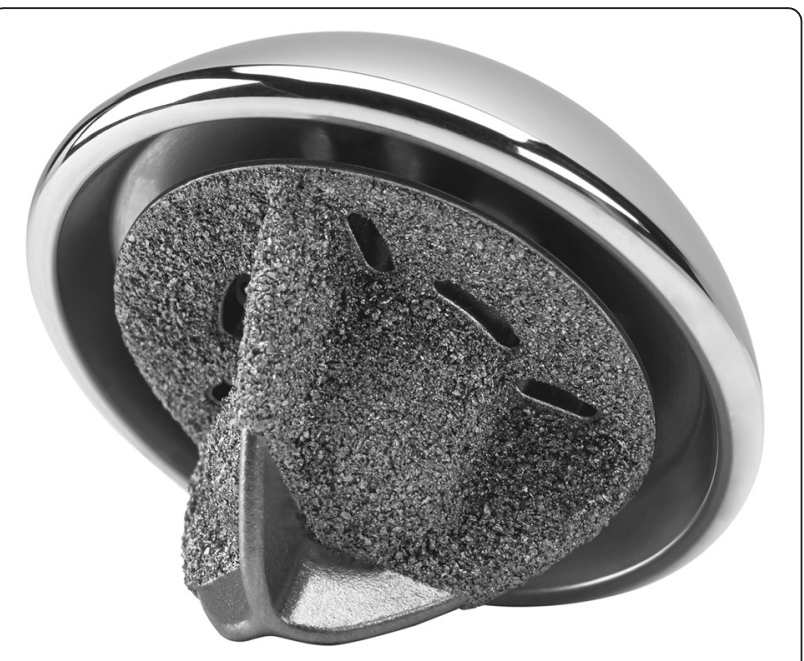

Fig. 4 The Simpliciti Stemless Prosthesis (Tornier, Bloomington, MN, US) (Figure provided by the manufacturer)

\section{Simpliciti Stemless Prosthesis}

Clinical use of the Simpliciti Stemless Prosthesis (Tornier, Bloomington, MN, US) began in France in 2010 (Fig. 4). It is presently the only FDA-approved stemless respectively canal-sparing implant. It comprises two pieces-a humeral implant and a head implant-which are available in different sizes. Churchill et al. [27] and Ho et al. $[18,28]$ both recently published results of canal-sparing respectively stemless shoulder arthroplasty with a 24-month follow-up in a total of 298 patients. Table 2 summarizes the indications. Both studies demonstrated improved outcomes, and no humeral-sided complications.

\section{Discussion}

Six different canal-sparing respectively stemless humeral implants are presently available on the market, four of which are described in published studies. The canalsparing respectively stemless shoulder prosthesis with metaphyseal anchoring is a relatively new concept that reportedly provides good outcomes that are comparable to stemmed designs in short and midterm evaluations $[19,21-23,27]$. All of the presently reviewed studies demonstrated substantial improvement after replacement. Moreover, the studies that compared the canalsparing respectively stemless design to stemmed implants showed no differences in outcomes related to the humeral component [21-23].

The indications for canal-sparing respectively stemless prosthesis are the same as for stemmed systems. Canalsparing respectively stemless implants cannot be used in cases with poor bone quality, metaphyseal cysts, osteopenia, osteoporosis, or other metabolic bone diseases [29], or in cases with fractures in the metaphyseal area that disturb adequate bony in-growth or primary implant stability.
However, there is not yet any test available to objectively determine bone quality pre- or intraoperatively [29]. Churchill et al. [18] described the use of a "thumb test" in which bone quality is intraoperatively assessed by compressing the surface of the neck cut with the thumb. Overall, the presently reviewed studies reported only a few isolated cases of loosening of the stemless component.

Among the various investigated canal-sparing respectively stemless prostheses, the main difference in design is that the Eclipse is inserted over a screw, while the TESS, the Simpliciti, and the Affinis prostheses are inserted using an impaction technique. It appears that the mechanism of force transmission when the Eclipse prosthesis is inserted over a screw differs from that during impaction implantation of the corolla of the TESS, the wings of the Affinis, or the Simpliciti prosthesis. This difference may explain the observed differences in the surrounding humeral bone, with changed bone mineral density seen on radiographs, which could be interpreted as stress shielding beneath the trunnion with the Eclipse prosthesis. These findings are not correlated with any negative clinical symptoms, and seem to be purely a radiographic phenomenon, at least at the midterm follow-up. Subgroup analysis of these patients reported by Habermeyer et al. [27] revealed no statistical significance in the patient cohort, with a minimum follow-up of 5 years.

One major advantage of the canal-sparing respectively stemless prosthesis design is that it can potentially be used in post-traumatic and deformity cases regardless of the humeral head-shaft configuration. Restoration of the glenohumeral center of rotation independently from the shaft is a key goal in secondary shoulder arthroplasty for fracture sequelae treatment [30]. Malunion resulting in metaphyseal-diaphyseal malalignment can make it difficult or even impossible to implant a stemmed or even a short-stemmed prosthesis. In such cases, corrective osteotomies are associated with poor results [31]. Reports of these types of special cases are limited to only rare single cases within the studies. Other advantages of the canalsparing respectively stemless prosthesis are that it can preserve bone stock of the proximal humerus, as well as avoid humeral stem-related complications in revision cases requiring stem removal. In a commentary, Athwal summarized the advantages of the canal-sparing respectively stemless implant as a theoretically decreased surgical time, less blood loss, bone preservation, and lower risk of intraoperative and potentially postoperative periprosthetic fractures. Canal-sparing respectively stemless prostheses are also suitable for posttraumatic joint reconstruction and, when needed, explantation is easier compared to with the stemmed version. Following explantation, a stemless prosthesis can be replaced by a standard-length primary implant [29]. 
For the purpose of this review, we chose to include all available literature evaluating anatomic canal-sparing respectively stemless humeral components in shoulder arthroplasty. This review article refers to only implant designs with metaphyseal fixation, and excludes humeral head resurfacing. It is much easier to achieve glenoid exposure for glenoid component implantation using canalsparing respectively stemless implants compared to with humeral head resurfacing $[3,20]$.

It must be noted that, all reviewed studies provide only short or midterm results, and include only a limited number of patients. Additionally, some studies were reported by the designer or co-developer of the investigated implant, which suggests the possibility of a certain bias. There are presently ongoing IDE trials, which will provide more robust and high-quality data on this topic.

\section{Conclusions}

All of the published studies describing anatomic canalsparing respectively stemless shoulder replacement showed promising clinical and radiological outcomes over short to midterm follow-up periods. To date, the available literature lacks well-designed clinical studies with at least midterm results.

\section{Disclaimer}

Peter Habermeyer receives patent fees for the Eclipse prosthesis from Arthrex, Inc. Mark Tauber and Frank Martetschläger are consultants for Arthrex, Inc. The other authors certify that they have no commercial associations (e.g. consultancies, stock ownership, equity interest, patent/ licensing arrangements, etc.) that might pose a conflict of interest in connection with the submitted article. Arthrex, Mathys, Tornier, and Zimmer Biomet own the copyrights and all other intellectual property rights related to the included pictures. All pictures are published with permission from Arthrex, Mathys, Tornier (an indirect subsidiary of Wright Medical Group N.V.), and Zimmer Biomet. This review article received no financial support, and Arthrex, Mathys, Tornier, and Zimmer Biomet are not responsible for the content of the review article aside from giving permission for the use of their photos.

\section{Availability of data and materials}

The authors are willing to share primary data related to this research upon request, presented in an additional file in a machine-readable format.

\section{Authors' contributions}

$\mathrm{NH}, \mathrm{MT}$, and FM designed the study, collected and analyzed the data, wrote the initial draft, and ensured the accuracy of the data and analysis. MM designed the study, analyzed the data, wrote the initial draft, and ensured the accuracy of the data and analysis. PH designed the study and ensured the accuracy of the data and analysis. All authors read and approved the final manuscript.

\section{Competing interest}

Peter Habermeyer receives patent fees for the Eclipse prosthesis from Arthrex, Inc. Mark Tauber and Frank Martetschläger are consultants for Arthrex, Inc. The other authors certify that they have no commercial associations (e.g. consultancies, stock ownership, equity interest, patent/ licensing arrangements, etc.) that might pose a conflict of interest in connection with the submitted article.

Arthrex, Mathys, Tornier, and Zimmer Biomet own the copyrights and all other intellectual property rights related to the included pictures. All pictures are published with permission from Arthrex, Mathys, Tornier (an indirect subsidiary of Wright Medical Group N.V.), and Zimmer Biomet. This review article received no financial support, and Arthrex, Mathys, Tornier, and
Zimmer Biomet are not responsible for the content of the review article aside from giving permission for the use of their photos.

\section{Consent to publish}

Not applicable

\section{Ethics and consent to participate}

Not applicable

\section{Financial competing interests}

Peter Habermeyer receives patent fees for the Eclipse prosthesis from Arthrex, Inc. Mark Tauber and Frank Martetschläger are consultants for Arthrex, Inc. The other authors certify that they have no commercial associations (e.g. consultancies, stock ownership, equity interest, patent/ licensing arrangements, etc.) that might pose a conflict of interest in connection with the submitted article.

\section{Author details}

'Department of Shoulder and Elbow Surgery, ATOS Clinic Munich, Effnerstraße 38, 81925 München, Germany. ${ }^{2}$ Trauma Department, Hannover Medical School, Carl-Neuberg-Str. 1, 30625 Hannover, Germany. ${ }^{3}$ Department of Traumatology and Sports Injuries, Paracelsus Medical University, Salzburg, Austria. ${ }^{4}$ Boston Shoulder Institute/Harvard Medical School, Boston, MA, USA. ${ }^{5}$ Department of Orthopaedic Sports Medicine, Klinikum rechts der Isar, Technical University, Munich, Germany.

Received: 25 June 2016 Accepted: 24 August 2016

Published online: 30 August 2016

\section{References}

1. Neer 2 nd CS. Articular replacement for the humeral head. J Bone Joint Surg Am. 1955:37-A:215-28.

2. Neer 2nd CS. Replacement arthroplasty for glenohumeral osteoarthritis. J Bone Joint Surg Am. 1974;56:1-13.

3. Churchill RS. Stemless shoulder arthroplasty: current status. J Shoulder Elbow Surg. 2014:23:1409-14. doi:10.1016/j.jse.2014.05.005.

4. Athwal GS, Sperling JW, Rispoli DM, Cofield RH. Periprosthetic humeral fractures during shoulder arthroplasty. J Bone Joint Surg Am. 2009;91:594603. doi:10.2106/JBJS.H.00439.

5. Bohsali KI, Wirth MA, Rockwood Jr CA. Complications of total shoulder arthroplasty. J Bone Joint Surg Am. 2006;88:2279-92. doi:10. 2106/JBJS.F.00125.

6. Chin PY, Sperling JW, Cofield RH, Schleck C. Complications of total shoulder arthroplasty: are they fewer or different? J Shoulder Elbow Surg. 2006;15:1922. doi:10.1016/j.jse.2005.05.005.

7. Deshmukh AV, Koris M, Zurakowski D, Thornhill TS. Total shoulder arthroplasty: long-term survivorship, functional outcome, and quality of life. J Shoulder Elbow Surg. 2005;14:471-9. doi:10.1016/j.jse.2005.02.009.

8. Farng E, Zingmond D, Krenek L, Soohoo NF. Factors predicting complication rates after primary shoulder arthroplasty. J Shoulder Elbow Surg. 2011;20:557-63. doi:10.1016/j.jse.2010.11.005.

9. Kumar S, Sperling JW, Haidukewych GH, Cofield RH. Periprosthetic humeral fractures after shoulder arthroplasty. J Bone Joint Surg Am. 2004;86-A:680-9.

10. Sperling JW, Cofield RH, Rowland CM. Minimum fifteen-year follow-up of Neer hemiarthroplasty and total shoulder arthroplasty in patients aged fifty years or younger. J Shoulder Elbow Surg. 2004;13:604-13. doi:10.1016/ S1058274604001296

11. Wirth MA, Rockwood Jr CA. Complications of total shoulder-replacement arthroplasty. J Bone Joint Surg Am. 1996;78:603-16.

12. Levy O, Copeland SA. Cementless surface replacement arthroplasty of the shoulder. 5- to 10-year results with the Copeland mark-2 prosthesis. J Bone Joint Surg Br. 2001;83:213-21.

13. Levy O, Copeland SA. Cementless surface replacement arthroplasty (Copeland CSRA) for osteoarthritis of the shoulder. J Shoulder Elbow Surg. 2004;13:266-71. doi:10.1016/S1058274604000229.

14. Levy O, Funk L, Sforza G, Copeland SA. Copeland surface replacement arthroplasty of the shoulder in rheumatoid arthritis. J Bone Joint Surg Am. 2004;86-A:512-8.

15. Mullett H, Levy O, Raj D, Even T, Abraham R, Copeland SA. Copeland surface replacement of the shoulder. Results of an hydroxyapatite-coated 
cementless implant in patients over 80 years of age. J Bone Joint Surg Br. 2007;89:1466-9. doi:10.1302/0301-620X.89B11.18850.

16. Al-Hadithy N, Domos P, Sewell MD, Naleem A, Papanna MC, Pandit R. Cementless surface replacement arthroplasty of the shoulder for osteoarthritis: results of fifty Mark III Copeland prosthesis from an independent center with four-year mean follow-up. J Shoulder Elbow Surg. 2012;21:1776-81. doi:10.1016/j.jse.2012.01.024.

17. Alizadehkhaiyat O, Kyriakos A, Singer MS, Frostick SP. Outcome of Copeland shoulder resurfacing arthroplasty with a 4-year mean follow-up. J Shoulder Elbow Surg. 2013;22:1352-8. doi:10.1016/j.jse.2013.01.027.

18. Churchill RS, Chuinard C, Wiater JM, Friedman R, Freehill M, Jacobson S, Spencer Jr E, Holloway GB, Wittstein J, Lassiter T, Smith M, Blaine T, Nicholson GP. Clinical and radiographic outcomes of the simpliciti canalsparing shoulder arthroplasty system: a prospective two-year multicenter study. J Bone Joint Surg Am. 2016;98:552-60. doi:10.2106/JBJS.15.00181.

19. Huguet D, DeClercq G, Rio B, Teissier J, Zipoli B, Group T. Results of a new stemless shoulder prosthesis: radiologic proof of maintained fixation and stability after a minimum of three years' follow-up. J Shoulder Elbow Surg. 2010;19:847-52. doi:10.1016/j.jse.2009.12.009.

20. Kadum B, Mafi N, Norberg S, Sayed-Noor AS. Results of the Total Evolutive Shoulder System (TESS): a single-centre study of 56 consecutive patients. Arch Orthop Trauma Surg. 2011;131:1623-9. doi:10.1007/s00402-011-1368-4.

21. Razmjou H, Holtby R, Christakis M, Axelrod T, Richards R. Impact of prosthetic design on clinical and radiologic outcomes of total shoulder arthroplasty: a prospective study. J Shoulder Elbow Surg. 2013;22:206-14. doi:10.1016/j.jse.2012.04.016.

22. Berth A, Pap G. Stemless shoulder prosthesis versus conventional anatomic shoulder prosthesis in patients with osteoarthritis: a comparison of the functional outcome after a minimum of two years follow-up. J Orthop Traumatol. 2013;14:31-7. doi:10.1007/s10195-012-0216-9.

23. Maier MW, Lauer S, Klotz MC, Bulhoff M, Spranz D, Zeifang F. Are there differences between stemless and conventional stemmed shoulder prostheses in the treatment of glenohumeral osteoarthritis? BMC Musculoskelet Disord. 2015;16:275. doi:10.1186/s12891-015-0723-y.

24. Bell SN, Coghlan JA. Short stem shoulder replacement. Int I Shoulder Surg. 2014;8:72-5. doi:10.4103/0973-6042.140113.

25. Schoch C, Huth J, Aghajev E, Bauer G, Mauch F. Die metaphysär verankerte Prothese bei posttraumatischer und primärer Omarthrose. Obere Extremität. 2011;6:275-81. doi:10.1007/s11678-011-0137-x.

26. Brunner UH, Fruth M, Rückl K, Magosch P, Tauber M, Resch H, Habermeyer P. Die schaftfreie Eclipse-Prothese - Indikation und mittelfristige Ergebnisse. Obere Extremität. 2012;7:22-8. doi:10.1007/s11678-011-0152-y.

27. Habermeyer $\mathrm{P}$, Lichtenberg $\mathrm{S}$, Tauber M, Magosch P. Midterm results of stemless shoulder arthroplasty: a prospective study. J Shoulder Elbow Surg. 2015;24:1463-72. doi:10.1016/j.jse.2015.02.023.

28. Ho AG, Gowda AL, Wiater JM. Stemless humeral component in total shoulder arthroplasty: 2-year age-related clinical outcomes. J Shoulder Elbow Surg. 2016. doi: 10.1016/j.jse.2016.02.023.

29. Athwal GS. Spare the canal: stemless shoulder arthroplasty is finally here: commentary on an article by R. Sean Churchill, MD, et al:. "Clinical and radiographic outcomes of the simpliciti canal-sparing shoulder arthroplasty system. A prospective two-year multicenter study". J Bone Joint Surg Am. 2016;98:e28. doi:10.2106/JBJS.15.01350

30. Kadum B, Hassany H, Wadsten M, Sayed-Noor A, Sjoden G. Geometrical analysis of stemless shoulder arthroplasty: a radiological study of seventy TESS total shoulder prostheses. Int Orthop. 2015. doi: 10.1007/s00264-015-2935-z.

31. Boileau P, Trojani C, Walch G, Krishnan SG, Romeo A, Sinnerton R. Shoulder arthroplasty for the treatment of the sequelae of fractures of the proximal humerus. J Shoulder Elbow Surg. 2001;10:299-308. doi:10. 1067/mse.2001.115985.

\section{Submit your next manuscript to BioMed Central and we will help you at every step:}

- We accept pre-submission inquiries

- Our selector tool helps you to find the most relevant journal

- We provide round the clock customer support

- Convenient online submission

- Thorough peer review

- Inclusion in PubMed and all major indexing services

- Maximum visibility for your research

Submit your manuscript at www.biomedcentral.com/submit
() BioMed Central 